\title{
Evaluation of bacteriological contamination pattern of open fractures of extremities in tertiary care hospital
}

\author{
Sourabh Jain, Ashok Kumar*, Anurag Chhabra, Krishan Kumar, Kulveer Chaudhary
}

Department of Orthopaedics, Maharaja Agarasen Medical College, Agroha, Hisar, Haryana, India

Received: 29 April 2021

Revised: 04 June 2021

Accepted: 05 June 2021

\author{
*Correspondence: \\ Dr. Ashok Kumar, \\ E-mail: drashokbagotia@gmail.com
}

Copyright: ( $)$ the author(s), publisher and licensee Medip Academy. This is an open-access article distributed under the terms of the Creative Commons Attribution Non-Commercial License, which permits unrestricted non-commercial use, distribution, and reproduction in any medium, provided the original work is properly cited.

\begin{abstract}
Background: Open fractures and associated complications like infection are fairly common in developing countries due to rising incidence of high velocity trauma. Primary goal of study is to evaluate the pattern of bacteriological contamination of open fractures of extremities in tertiary care hospital.

Methods: A total of 316 patients of all the age group, both the sexes with open fractures of extremities presented within 6 hours were taken in to study. $1^{\text {st }}$ swab taken at the time of primary wound examination followed by $2^{\text {nd }}$ culture swab on just after debridement followed by $3^{\text {rd }}$ culture swab on the day of $1^{\text {st }}$ aseptic dressing followed by $4^{\text {th }}$ culture swab if infection continues or asepsis score is more than 20 till the duration of 4 days. Culture and sensitivity reports were collected for studying pattern of bacterial isolates and their sensitivity.

Results: Infection developed in $22.5 \%$ of the patients with open fractures of extremities in whom most of bacterial infections were caused by gram-negative organisms (80.3\%). Cultures on admission were positive in 41 patients, out of which 11 patients had developed infection in the final cultures but with different flora. While cultures taken at $1^{\text {st }}$ aseptic dressing were found to be positive in 51 cases, out of which 31 had developed infection with prognostic value of $57 \%$.

Conclusions: We concluded that cultures obtained at $1^{\text {st }}$ aseptic dressing are far more predictive than pre and postdebridement cultures in management of patients with open fractures of extremities and are important in formulating an antibiotic policy.
\end{abstract}

Keywords: Open fractures, Debridement, Infection, Antibiotics

\section{INTRODUCTION}

Open fractures are fairly common in developing countries due to rising incidence of high velocity trauma. Infection at a site of traumatic wounds is a common complication of open fractures. Chronic osteomyelitis, non-union, loss of function are serious outcomes of deep fracture site infection. Primary goal in management of open fracture is prevention of infection of bones and soft tissue by early debridement, irrigation of wound and administration of antibiotics with stabilization of fractures. ${ }^{1}$
This serious nature of open fracture has been understood since antiquity. Fractures are classified as open when they communicate with the outside environment through a wound and are usually caused by high energy trauma. According to Gustilo-Anderson (G-A), open fractures are classified into three major types, based on the mechanism of injury, the degree of soft-tissue damage, the configuration of the fracture, and the level of contamination (G-A). The bacterial contamination of bones and soft tissue in open fracture leads to an infection rate of up to $50 \% .^{2-5}$ 
Table 1: Modified Gustilo and Anderson classification of open fractures (adapted from Okike and Bhattacharyya, 2006). ${ }^{6}$

\begin{tabular}{|lll|} 
Grade & Definition & $\begin{array}{l}\text { Historical infection rate } \\
(\%)\end{array}$ \\
\hline I & Wound $<1 \mathrm{~cm}$; minimal contamination, comminution, and soft-tissue damage & $0-2$ \\
\hline II & Wound $>1 \mathrm{~cm}$; moderate soft-tissue damage, minimal periosteal stripping & $2-5$ \\
\hline IIIA & Severe soft-tissue damage and substantial contamination; coverage adequate & $5-10$ \\
\hline IIIB & Severe soft-tissue damage and substantial contamination; coverage inadequate & $10-50$ \\
\hline IIIC & Arterial injury requiring repair & $25-50$ \\
\hline
\end{tabular}

Up to $70 \%$ of open fractures are contaminated at the time of injury mostly by organisms from the skin and the environment. Several large series from multiple centres have identified the most common organisms present and have led to the acceptance of using broad spectrum antibiotics; cephalosporins augmented by aminoglycosides in grade III open fractures and penicillin in farmyard injuries.

Contamination may also occur in the course of treatment. Pathogens and their resistance against therapeutic agents change with time and vary in different regions. The selection of antibiotics to treat the contaminating organisms and coverage against the infection is still controversial. These bacterial patterns are important in developing antibiotic protocols for prophylaxis and empirical treatment. ${ }^{7}$

The aim of our study was to describe the pattern of bacterial contamination and antibiotic susceptibility and possible resistance to antibiotic agents from open fractures coming to our institute within 6 hours of injury. Local studies on these patterns are lacking in our area. This specific prophylactic antibiotic treatment based on prevalent microbes in our region will be helpful in preventing dreadful chronic complications associated with deep tissue infection in open fractures. There would be also a decline in cost of treatment to patient and antibiotic resistance as a proper regimen will be formed for management of patients.

\section{METHODS}

\section{Study design}

Following approval from institutional review board, a prospective study was conducted on a total of 316 patients with open fractures of extremities admitted in accident and emergency department of Maharaja Agrasen Medical College, Agroha, Hisar between $1^{\text {st }}$ January 2019 to $31^{\text {st }}$ March 2020. Patients were informed about the study in all respects and informed consent was obtained from each patient.

Statistical testing was conducted with the statistical package for the social science system version statistical package for the social sciences (SPSS) 20.0.

\section{Inclusion criteria}

All patients with open fractures of extremities due to road traffic accident, household fall, sports injury, crush injury, fall from height, assault and others (burn, electric shock) with time of injury less than 6 hours were included in the study.

\section{Exclusion criteria}

Patients having diabetes mellitus and peripheral vascular disease; patients with open fracture primarily treated somewhere else; patients who had received oral or parenteral antibiotics before presentation; patients who did not have definitive treatment at our institution; and patients not willing to be part of this study were excluded.

All the patients meeting the inclusion criteria were selected to study bacterial flora in open fractures of extremities and their antibiotic sensitivity was done on isolation of bacteria. On arrival in emergency, wounds were examined, pre and post debridement wound swabs for aerobic culture in type I to type IIIA, aerobic and anaerobic culture in type IIIB and IIIC were taken.

\section{Swab collection times}

Swabs were collected: at the time of admission on first inspection of wound, after wound debridement, at time of first aseptic dressing, and in patients with asepsis score is more than 20 till duration of 4 days.

All the swab samples were sent to microbiology department. Preliminary gram staining was performed to determine the likely organism present. The samples were inoculated on blood agar, MacConkey agar, Robertson's cooked meat and glucose broth, which were incubated for $24-48$ hours at $37^{\circ} \mathrm{C}$. All the isolates were identified by colony morphology, gram stain and biochemical tests using the standard procedures. Each isolates were screened for antibiotic sensitivity testing by the Kirby-Bauer disc diffusion method including-ampicillin, ampicillinsulbactam, amoxicillin-clavulanic acid, piperacillintazobactam, ceftazidime, cefitaxime, gentamicin, amikacin, clindamycin, erythromycin, chloramphenicol, linezolid, vancomycin, clotrimazole, cefepime, imipenem, 
meropenem, cefoperazone-sulbactam, tetracyclin, ciprofloxacin and aztreonam.

\section{RESULTS}

The present study was done at Department of Orthopaedic Surgery, Maharaja Agrasen Medical College, Agroha, on a total of 316 patients of open fractures of extremities who met the inclusion criteria attended accident and emergency department from 1st January 2019 to 31st March 2020 and these were analyzed for overall results.

Most of the patients in the present study were males $(84.5 \%)$ with male to female ratio are 5.4:1. The gender wise distribution is shown in Table 2.

Table 2: Gender wise distribution.

\begin{tabular}{|lll|}
\hline Sex & No. of patients & Percentage $(\%)$ \\
\hline Female & 49 & 15.5 \\
\hline Male & 267 & 84.5 \\
\hline Total & 316 & 100.0 \\
\hline
\end{tabular}

In our study, most of patients were found in the age group of 21-50 years as shown in Table 3. This is due to the fact that this age group belongs to the middle age and they are more involved in outdoor activities and road traffic accident than young and old age people.

Table 3: Age wise distribution.

\begin{tabular}{|lll|}
\hline Age group & No. of patients & Percentage $(\%)$ \\
\hline $\mathbf{1 - 2 0}$ & 57 & 17.9 \\
\hline $\mathbf{2 1 - 5 0}$ & 219 & 68.6 \\
\hline $\mathbf{> 5 1}$ & 40 & 12.5 \\
\hline Total & 316 & 100.0 \\
\hline
\end{tabular}

In our study, the most common cause of open fractures of extremities was found to be road traffic accident, accounting for 204 cases $(65 \%)$. We found maximum cases $226(72 \%)$ of open fractures in lower limb, among which tibia was the most common fractured bone with 121 (38\%) cases with right sided predominance $(58.5 \%)$. Out of 316 patients, most of cases $124(39 \%)$ of open fractures were Gustilo II followed by type IIIA (33\%).

On admission, pre-debridement swabs were collected from all 316 patients of open fractures of extremities. Out of which, $41(13 \%)$ cases were found to be culture positive. Most of the cultures showed gram-positive growth (58.5\%). Among which, Staphylococcus aureus was found to be predominant contaminant. Post-debridement swabs showed growth in only $3(0.9 \%)$ patients, in whom Staphylococcus aureus, E. coli and Pseudomonas were found to be in equal proportion.

$1^{\text {st }}$ aseptic dressing cultures showed growth in $51(16.1 \%)$ cases. Out of 51 , only 3 patients were those who also showed growth in pre-debridement cultures but with different organisms. All positive post-debridement culture patients became negative at this stage. Most of the positive $1^{\text {st }}$ aseptic dressing cultures showed gram-negative growth $(84.3 \%)$ as compared to gram-positive $(15.7 \%)$. Among which, Pseudomonas was found to be most common isolate.

In our study, we had 91 patients in whom the discharge continued and asepsis score was found over 20. Out of which, infection developed in 71 patients and most of bacterial infections were caused by gram-negative organisms (80\%). Among gram-negative, Pseudomonas $(35.1 \%)$ was the most common infecting organism while Staphylococcus aureus $(100 \%)$ was the predominant culprit among gram-positive isolates. The distribution pattern of bacterial flora at different stage of wound management is shown in Table 4.

On analysis, we found that cultures on admission (predebridement cultures) were positive in only 41 (13\%) of the patients. Out of which, 11 patients had developed infection in the final cultures but with different flora. Similarly, negative initial cultures did not rule out the probability of infection later on, as many cases (60) negative for the growth in initial cultures showed growth in final cultures. While cultures taken at $1^{\text {st }}$ aseptic dressing day was found to be more sensitive as 31 (61\%) out of 51 cases had developed infection in the final cultures and in $57 \%$ of the cases, similar type of organisms were isolated. Thus cultures obtained at $1^{\text {st }}$ aseptic dressing had a better prognostic value $(57 \%)$ as compared to initial cultures. The predictive value of pre- and postdebridement cultures for development of infection in the final cultures was found to be statistically insignificant as $\mathrm{p}$ value was $>0.05$ as compared to that of $1^{\text {st }}$ aseptic dressing cultures which had $\mathrm{p}$ value $<0.05$.

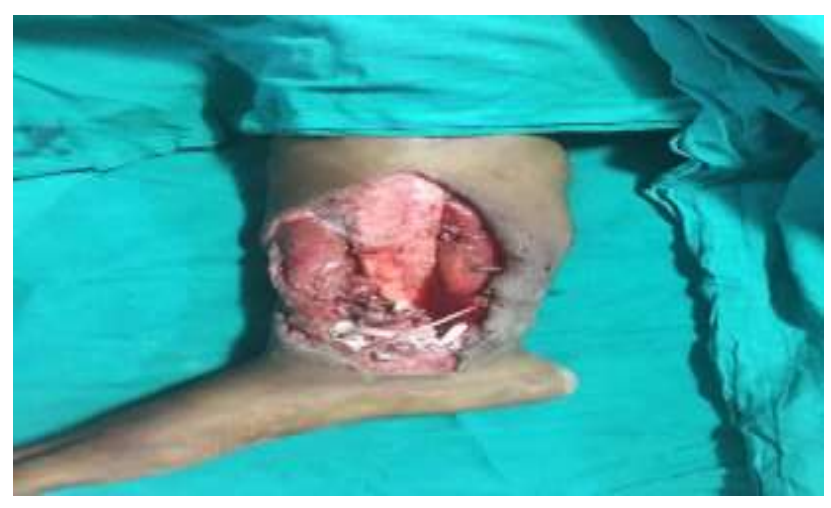

Figure 1: Pre-debridement wound.

In the present study, all gram-positive organisms showed high susceptibility to linezolid, vancomycin and cefotaxime over $90 \%, 85.7 \%$ and $78.8 \%$ respectively. Other antibiotics were less susceptible $(<50 \%)$ and showed high resistance to gram-positive isolates. Antimicrobial susceptibility pattern of gram-positive isolates is shown in Table 5 and 6. 
Table 4: Bacterial flora at different stages of wound management.

\begin{tabular}{|lllll|}
\hline $\begin{array}{l}\text { Cultures at different stages of wound } \\
\text { management }\end{array}$ & No growth & $\begin{array}{l}\text { Growth } \\
\text { seen }\end{array}$ & $\begin{array}{l}\text { Gram-positive } \\
\text { growth }(\%)\end{array}$ & $\begin{array}{l}\text { Gram-negative } \\
\text { growth }(\%)\end{array}$ \\
\hline Pre-debridement cultures $(\mathbf{n = 3 1 6 )}$ & 275 & 41 & 58.5 & 41.5 \\
\hline Post-debridement cultures $(\mathbf{n = 3 1 6 )}$ & 313 & 3 & 34 & 66 \\
\hline $\mathbf{1}^{\text {st }}$ aseptic dressing cultures $(\mathbf{n = 3 1 6 )}$ & 265 & 51 & 16 & 84 \\
\hline Final cultures $(\mathbf{n = 9 1 )}$ & 20 & 71 & 19.7 & 80.3 \\
\hline
\end{tabular}

Table 5: Antibiotic susceptibility pattern of gram-positive isolates.

\begin{tabular}{|llllllll|}
\hline \multirow{2}{*}{ Gram-positive organism } & \multicolumn{2}{l}{ Antimicrobial agents $(\%)$} & & & & \\
& SAM & AMK & AMC & FEP & CFP & CTX & CIP \\
\hline Staphylococcus aureus $(\mathbf{n}=14)$ & 71.4 & 71.4 & 21.4 & 14.2 & 28.5 & 78.8 & 64.2 \\
\hline
\end{tabular}

Table 6: Antibiotic susceptibility pattern of gram-positive isolates.

\begin{tabular}{|c|c|c|c|c|c|c|c|}
\hline \multirow{2}{*}{ Gram-positive organism } & \multicolumn{7}{|c|}{ Antimicrobial agents (\%) } \\
\hline & $\mathbf{V A N}$ & LZD & GEN & IMP & CLI & CHL & TET \\
\hline Staphylococcus aureus & 85.7 & 92.8 & 21.4 & - & 21.4 & 42.8 & 42.8 \\
\hline
\end{tabular}

Table 7: Antibiotic susceptibility pattern of gram-negative isolates.

\begin{tabular}{|c|c|c|c|c|c|c|c|}
\hline \multirow{2}{*}{ Gram-negative organisms } & \multicolumn{7}{|c|}{ Antimicrobial agents (\%) } \\
\hline & IMP & AMK & CIP & CEP & AMP & SAM & CHL \\
\hline Acinetobacterbaumanni $(\mathrm{n}=7)$ & 85.7 & 85.7 & 71.4 & 42.8 & - & - & - \\
\hline Escherichia coli $(n=7)$ & 28.5 & 71.4 & 71.4 & - & 14.3 & 57.1 & 57.1 \\
\hline Pseudomonas aeruginosa $(\mathrm{n}=20)$ & 90 & 85 & 85 & 70 & - & 10 & - \\
\hline Klebsiella $(\mathrm{n}=12)$ & - & 75 & 75 & 58.3 & - & - & - \\
\hline Citrobacter $(\mathrm{n}=11)$ & 54.5 & 36.3 & 27.2 & 45.5 & - & 36.3 & - \\
\hline
\end{tabular}

Table 8: Antibiotic susceptibility pattern of gram-negative isolates.

\begin{tabular}{|c|c|c|c|c|c|c|c|c|}
\hline \multirow{2}{*}{ Gram-negative organisms } & \multicolumn{8}{|c|}{ Antimicrobial agents (\%) } \\
\hline & GEN & AMC & ATM & MEM & TZP & TET & CTX & CAZ \\
\hline Acinetobacterbaumanni $(\mathrm{n}=7)$ & - & - & - & - & - & - & - & \\
\hline Escherichia coli $(\mathrm{n}=7)$ & 57.1 & 28.2 & - & 14.3 & 14.3 & 28.5 & - & \\
\hline Pseudomonas aeruginosa $(\mathrm{n}=20)$ & 45 & 35 & 20 & - & 80 & - & 15 & 75 \\
\hline Klebsiella $(\mathrm{n}=12)$ & - & - & - & 58.3 & - & - & - & - \\
\hline Citrobacter $(\mathrm{n}=11)$ & - & 9.1 & - & 18.2 & 36.3 & 45.5 & - & - \\
\hline
\end{tabular}

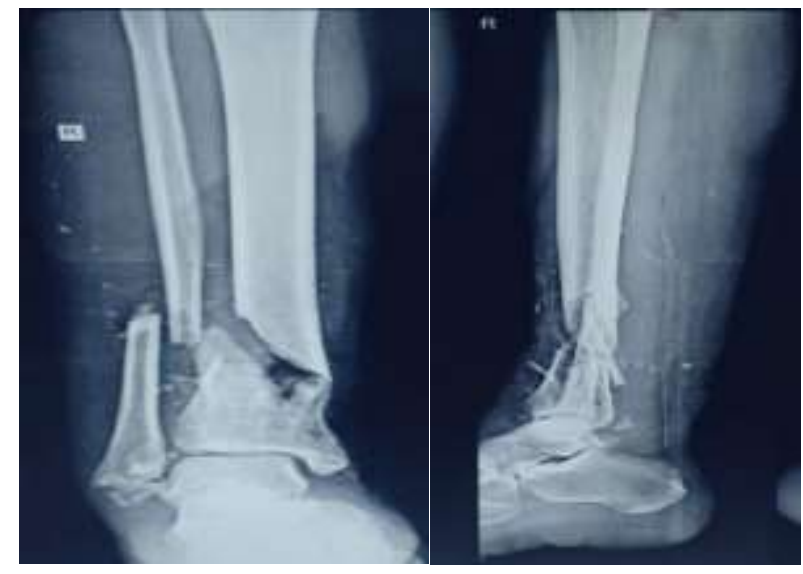

Figure 2: X-ray image.

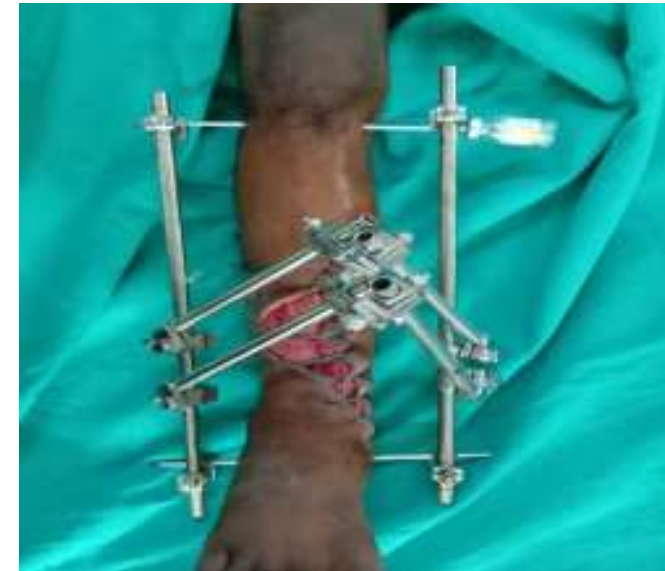

Figure 3: Post-debridement wound. 


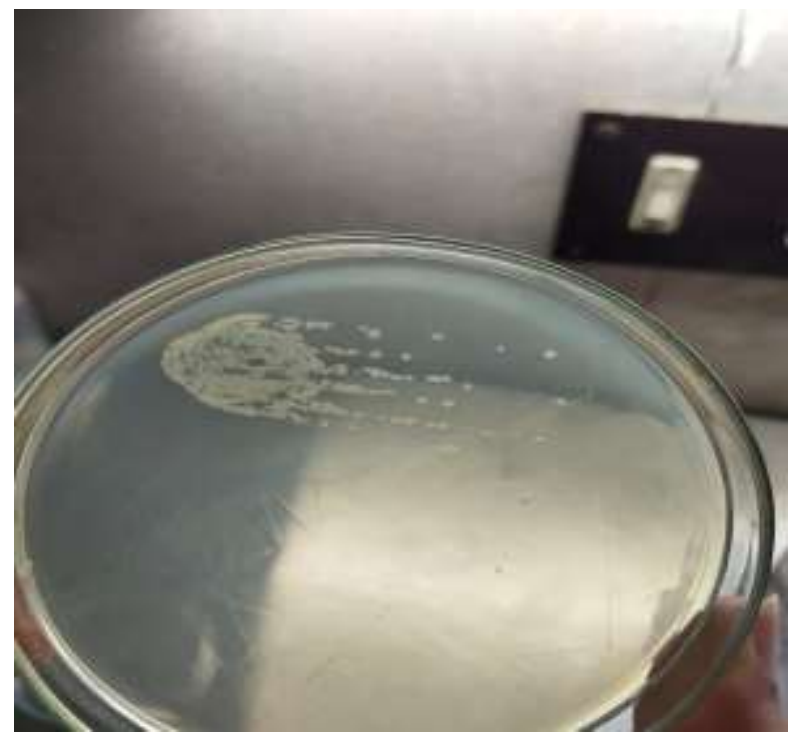

Figure 4: Pseudomonas growth.

In the present study, all gram-negative isolates except Citrobacter showed high susceptibility to amikacin and ciprofloxacin. Antimicrobial susceptibility pattern of gram-negative isolates is shown in Table 7 and 8 .

\section{DISCUSSION}

The present study was conducted on a total of 316 patients of open fractures of extremities who were brought to A and E department of our institution from $1^{\text {st }}$ January 2019 to $31^{\text {st }}$ March 2020.

In the present study, maximum numbers of patients were found in the age group of 21-50 years. The study conducted by Agarwal et al and Mangala et al also shows the same finding. ${ }^{9,12}$

In our study, out of 316 patients there were 267 males and 49 females with male to female ratio is 5.4:1. The study conducted by Lingaraj et al and Yishak et al also shows male preponderance. ${ }^{10,14}$

In the present study, road traffic accident (RTA) was found to be most common cause of open fractures, accounting for $204(65 \%)$ cases. The study conducted by Agarwal et al and Bhatty et al also noticed the same thing., ${ }^{9,13}$

In our study, we found maximum number of cases 226 (72\%) of open fractures in lower limbs. Agarwal, et al, Yishak et al and Mangala et al also shows the same finding. ${ }^{9,12,14}$

In the present study, right side was found to be affected more commonly, accounting for $185(58.5 \%)$ cases which is comparable to study conducted by Faisham et al. ${ }^{8}$

In the present study, tibia and fibula was the most common fractured bone, accounting for $38 \%$ cases. Agarwal et al and Mangala et al also noticed same finding., ${ }^{9,12}$
In the present study, cultures obtained at the time of admission (pre and post-debridement) were found to be of no value in predicting and treating the infections as none of the organisms grown on these cultures eventually caused infection. These findings are consistent with those found by Mangala et al and Bhatty et al. ${ }^{12,13}$

In the present study, cultures obtained at $1^{\text {st }}$ aseptic dressing were found to be more representative in predicting the infecting organisms as $31(61 \%)$ out of 51 cases had developed infection in the final cultures and in $57 \%$ of the cases, similar type of organisms were isolated. These findings are consistent with those found by Agarwal et al, who also noticed that the infecting organisms were the same as that in the $1^{\text {st }}$ aseptic dressing swabs in $80 \%$ of the cases. ${ }^{9}$

In our study, most of bacterial infections in open fracture wounds were caused by gram-negative organisms (80.3\%) with Pseudomonas and Klebsiella were the most predominant gram negative isolates. These findings are consistent with those found by Sitati et al. ${ }^{11}$

In the present study, Staphylococcus aureus was found to be predominant gram-positive isolates. Mangala et al and Bhatty et al noticed the same thing. ${ }^{12,13}$

In the present study, linezolid $(92.8 \%)$ and vancomycin $(85.7 \%)$ were found to be the most effective antibiotics against the tested gram-positive organisms. However, these drugs are costly and not to be recommended for prophylaxis to protect their efficacy. In our study, grampositive organisms also showed high susceptibility to $3^{\text {rd }}$ generation cephalosporins (cefotaxime 78.8\%) and these findings are consistent with those found by Sitati et al. ${ }^{11}$

In the present study, amikacin and ciprofloxacin were found to be the most effective antibiotics against the tested gram-negative organisms except Citrobacter and these findings are consistent with those found by Sitati et al and Agarwal et al. ${ }^{9,11}$

\section{CONCLUSION}

In our study, we concluded that cultures obtained at $1^{\text {st }}$ aseptic dressing are far more predictive than pre- and postdebridement cultures in management of patients with open fractures of extremities and are important in formulating an antibiotic policy. It is therefore recommended that cultures obtained at $1^{\text {st }}$ aseptic dressing will provide guidance regarding the choice of antimicrobial therapy, which when combined with a thorough wound debridement will enable an early wound closure and lesser complications.

\section{Funding: No funding sources Conflict of interest: None declared}

Ethical approval: The study was approved by the institutional ethics committee 


\section{REFERENCES}

1. Lawrence RM, Hoeprich PD, Huston AC, Benson DR, Riggins RS. Quantitative microbiology of traumatic orthopedic wounds. J Clin Microbiol. 1978;8:673-5.

2. Anglen JO. Comparison of soap and antibiotic solutions for irrigation of lower-limb open fracture wounds. A prospective, randomized study. J Bone Joint Surg Am. 2005;87:1415-22.

3. Hauser CJ, Adams CA Jr., Eachempati SR. Council of the Surgical Infection Society. Surgical Infection Society guideline: Prophylactic antibiotic use in open fractures: An evidence-based guideline. Surg Infect. 2006;7:379-405.

4. Zalavras CG, Marcus RE, Levin LS, Patzakis MJ. Management of open fractures and subsequent complications. J Bone Joint Surg Am. 2007;89:8845.

5. Gustilo RB, Anderson JT. Prevention of infection in the treatment of one thousand and twenty-five open fractures of long bones: retrospective and prospective analyses. J Bone Joint Surg Am. 1976;58:453-8.

6. Okike K, Bhattacharyya $T$. Trends in the management of open fractures. J Bone Joint Surg Am. 2006;88:2739-48.

7. Patzakis M, Harvey P Jr., Iveler D. The role of antibiotics in management of open fractures. J Bone Joint Surg Am. 1974;56:532-41.

8. Faisham WI, Nordin S, Aidura M. Bacteriological study and its role in the management of open tibial fracture. Med J Malaysia. 2001;56:201-6.
9. Agarwal D, Maheshwari R, Agrawal A, Chauhan VD, Juyal A. To study the pattern of bacterial isolates in open fractures. J Orthop Traumatol Rehabil. 2015;8:1-5.

10. Lingaraj R, Santoshi JA, Devi S, Najimudeen S, Gnanadoss JJ, Kanagasabai, R, et al. Predebridement wound culture in open fractures does not predict postoperative wound infection: A pilot study. J Nat Sci Biol Med. 2015;6:63-8.

11. Sitati FC, Mosi PO, Mwangi JC. Early Bacterial Cultures from Open Fractures - Differences before and after debridement. Ann Afr Surg. 2017;14:66-70.

12. Mangala A, Arthi K, Deepa R. Comparison of predebridement and debridement cultures in predicting postoperative infections in compound fractures. J Clin Diagnostic Res. 2018;12:6-9.

13. Bhatty S, Paul R, Kaur H. Study of microbiological flora and role of primary bacterial cultures in management of open fractures of long bones. Int J Orthop Sci. 2018;4:91-4.

14. Abraham Y, Wamisho BL. Microbial susceptibility of bacteria isolated from open fracture wounds. Afr J Microbiol Res. 2009;3:939-51.

Cite this article as: Jain S, Kumar A, Chhabra A, Kumar K. Evaluation of bacteriological contamination pattern of open fractures of extremities in tertiary care hospital. Int J Res Orthop 2021;7:800-5. 